\title{
Carbohydrate Supplement Drink
}

National Cancer Institute

\section{Source}

National Cancer Institute. Carbohydrate Supplement Drink. NCI Thesaurus. Code C107165.

A nutritional supplement drink containing $12.5 \%$ carbohydrates, which may enhance recovery following gastrointestinal (GI) surgery. Oral intake of the carbohydrate drink before surgery may prevent insulin resistance and associated hyperglycemia. It may also maintain adequate protein balance and muscle function. Ultimately, giving carbohydrates immediately before surgery may improve overall recovery time and return of Gl function. It may also decrease muscle loss. 